\title{
DIAGNÓSTICO SOCIOAMBIENTAL DO ENTORNO DA MICROBACIA HIDROGRÁFICA DO RIACHO NAMORADO NO MUNICÍPIO DE SÃO JOÃO DO CARIRI-PB
}

\author{
ENVIRONMENTAL DIAGNOSIS OF THE VALENTINE CREEK \\ WATERSHED HYDROGRAPHIC AND SURROUNDING REGION OF \\ SÃO JOÃO DO CARIRI-PB
}

\section{DIAGNOSTICO AMBIENTAL DE MEDIO AMBIENTE DE LA CUENCA DELNOVIO HIDROGRÁFICA CREEK EN LA CIUDAD DE SÃO JOÃO $D O C A R I R I-P B$}

Telma Lucia Bezerra Alves

Geógrafa, Bolsista CNPq, Mestre em Recursos Naturais e Doutoranda pelo Programa de Pós-Graduação em Recursos Naturais da Universidade Federal de Campina Grande, UFCG. Rua Aprígio Veloso, 882, Bairro Universitário, 58429-140, Campina Grande-PB

E-mail: telmalu@yahoo.com.br

Pedro Vieira de Azevedo Professor do Departamento de Ciências Atmosféricas- DCA, Universidade Federal de Campina Grande, UFCG.

Rua Aprígio Veloso, 882, Bairro Universitário, 58429-140, Campina Grande-PB

E-mail: pvieira@dca.ufcg.edu.br

Andre Aires de Farias

Licenciado em Ciências Agrárias, Mestre em Recursos Naturais e Doutorando pelo Programa de PósGraduação em Recursos Naturais da Universidade Federal de Campina Grande, UFCG. Rua Aprígio Veloso, 882, Bairro Universitário, 58429-140, Campina Grande-PB

E-mail: andreaires61@hotmail.com

\section{Resumo}

Dados dos aspectos sociais da população rural da Microbacia Hidrográfica Riacho Namorado e circunvizinhança, no município de São João do Cariri - PB, foram usados na realização do diagnóstico socioambiental e identificação do perfil dos proprietários rurais. Foram aplicados 25 questionários, seguindo a nomenclatura da Secretaria de Saúde do município. Foram também registradas as coordenadas geográficas de cada propriedade rural para posterior visualização da distribuição das propriedades em uma imagem de satélite da área de estudo. Os principais resultados indicaram que a população amostrada apresenta uma distribuição de faixa etária equilibrada, nível de escolaridade médio até o $5^{\circ}$ ano incompleto, são proprietários das terras e residentes a mais de dez anos na região. As famílias utilizam lenha como fonte energética, associada 
ao gás GLP. As fontes principais de água são cisternas e açudes e os resíduos sólidos são queimados ou eliminados livremente no ambiente. A agricultura e a pecuária são as principais atividades econômicas das propriedades, a renda é composta por apenas um salário mínimo e a produção agropecuária é basicamente para a subsistência das famílias.

Palavras-chave: desenvolvimento social, meio ambiente, semiárido, sustentabilidade.

\begin{abstract}
Data on the social aspects of the rural population of Valentine Creek Watershed Basin and surrounding region, municipality of the ray tracing - $\mathrm{PB}$, were used in diagnosis and identification of social and environmental profile of the landowners. 25 questionnaires were applied, following the nomenclature of Health Department of the municipality. We also recorded the geographic coordinates of each rural property for later viewing of the distribution of properties in a satellite image of the study area. Results indicated that the population sampled has a balance distribution of age, average education level until the 5th year incomplete, are landowners and residents for over ten years in the region. Families use firewood as energy source associated with LPG. The main sources of water are tanks and ponds and solid waste are burned or disposed freely in the environment. Agriculture and livestock are the main economic activities of the properties, the income is comprised of only a minimum wage and agricultural production is primarily for the livelihood of families.
\end{abstract}

Keywords: social development, environment, semiarid, sustainability.

\title{
Resumen
}

Datos sobre los aspectos sociales de la población rural de la cuenca de San Valentín Cuenca del Arroyo y la región circundante, en el municipio de trazado de rayos - PB, fueron utilizados en el diagnóstico y la identificación del perfil social y ambiental de los terratenientes. 25 cuestionarios fueron aplicados, siguiendo la nomenclatura de Departamento de Salud del municipio. También se registraronlas coordenadas geográficas de cada propiedad rural para su posterior visualización de la distribución de las propiedades de una imagen de satélite del área de estudio. Los resultados indicaron que la población de la muestra tieneuna distribución equilibrada de edad, nivel de educación media incompleta hasta el año quinto, son los propietarios y residentes por más de diez años en la región. Las familias utilizan leña como fuente de energía asociado con GLP. Las principales fuentes de agua son los tanques y los estanques y los residuos sólidos son quemados o desechados libremente en el medio ambiente. La agricultura y la ganadería son las principales actividades económicas de las propiedades, los ingresos se compone de sólo un salario mínimo y la producción agrícola es principalmente para el sustento de las familias.

Palabras-Clave: desarrollo social, medio ambiente, semiáridas, sostenibilidad.

Ateliê Geográfico Goiânia-GO v. 6, n. $4 \quad$ Dez/2012 $\quad$ p.88-109 Página 89




\section{Introdução}

O homem sempre teve a necessidade de estabelecer unidades espaciais e temporais bem constituídas na superfície terrestre para melhor intervir, observar, acompanhar e compreender as relações existentes entre ele e o espaço no qual está inserido (LAMONICA, 2002). Assim, a bacia hidrográfica é entendida como uma unidade básica de análise e planejamento ambiental, por permitir conhecer e avaliar os seus diversos componentes, processos e interações (BOTELHO \& SILVA, 2004). No espaço das bacias hidrográficas os esforços associados a conservação dos recursos naturais devem ser integrados na solução conjunta de problemas como: erosão, desmatamento, poluição dos corpos hídricos, dentre outros, visando a melhoria e bemestar das comunidades. De acordo com Vilaça et al. (2009), o comportamento de uma bacia hidrográfica ao longo do tempo é causado por dois fatores: naturais, responsáveis pela pré-disposição do meio à degradação ambiental; e antrópicos, onde as atividades humanas interferem de forma direta ou indireta no funcionamento da bacia.

As ações de planejamento para utilização e intervenções racionais nas bacias hidrográficas conduzem ao desenvolvimento rural sustentável, no qual as comunidades apresentem condições de vida satisfatórias em um ambiente equilibrado, conhecendo e convivendo adequadamente com os espaços nos quais estão inseridas. Para Martinho (2000), o desenvolvimento rural surge como uma perspectiva constituinte e relevante do processo de desenvolvimento sustentável. Pode ser definido como a melhoria das condições de vida das pessoas residentes nas áreas rurais, através de processos sociais que respeitem e articulem os seguintes princípios: eficiência econômica, equidade social e territorial, qualidade ambiental, sustentabilidade, participação democrática e responsabilidade cívica.

Para facilitar o gerenciamento dos recursos naturais, o território brasileiro foi dividido hidrograficamente (Conselho Nacional de Recursos Hídricos) em doze regiões hidrográficas, respaldado nos diferentes ecossistemas e caráter econômico, social e cultural existentes no país. Os Estados brasileiros por sua vez, no âmbito dos seus territórios, organizaram as divisões hidrográficas para fins de gestão, utilizando diferentes critérios (ANA, 2011). No contexto local, destaca-se que o Estado da Paraíba 
está dividido em onze bacias hidrográficas: Piranhas, Paraíba, Jacu, Curimataú, Camaratuba, Guaju, Mamanguape, Gramame, Miriri, Trairí e Abiaí.

Um diagnóstico socioeconômico visa analisar a situação social, econômica e tecnológica da população do meio rural (produtor e núcleo familiar), no sentido de se avaliar a deterioração socioeconômica das famílias residentes em bacias hidrográficas. Com isso, têm-se condições de elaborar recomendações em um projeto no sentido de elevar a qualidade e o nível de vida na respectiva bacia ou microbacia. Tão importante quanto à caracterização ambiental é o "retrato" socioeconômico obtido em uma determinada região, pois existe uma interdependência entre ambos, uma vez que o meio ambiente, ao ser destruído pelo homem, deteriora-se e auferem menos riquezas, mais doenças e problemas, deteriorando, por conseguinte, o homem também (ROCHA, 1997).

Nesse contexto, o presente estudo objetivou a realização de um diagnóstico socioambiental e identificação do perfil dos proprietários rurais e moradores da Microbacia Hidrográfica Riacho Namorado e circunvizinhança, no município de São João do Cariri-PB.

\section{Material e Métodos}

Localização Geográfica da área de estudo

A pesquisa foi realizada na Microbacia Hidrográfica do Riacho Namorado, localizada no município de São João do Cariri ("latitude: $7^{\circ} 20^{\prime} 12$ " S, longitude: $35^{\circ} 28^{\prime} 35^{\prime}$ ' W), inserido na mesorregião da Borborema e microrregião do Cariri Oriental do Estado da Paraíba (Fig. 1): 


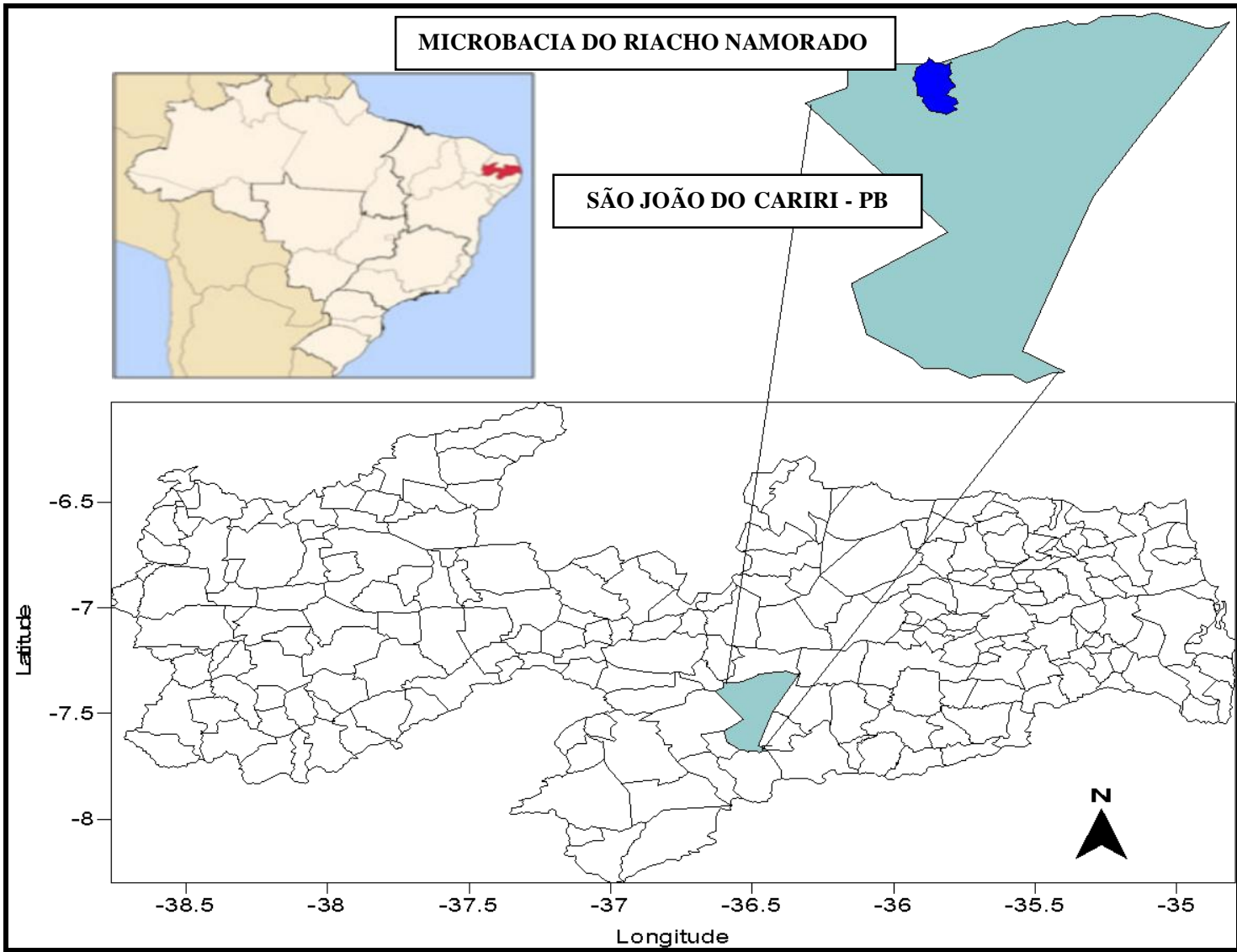

Figura 1: Localização geográfica do município de São João do Cariri-PB e da microbacia do Riacho Namorado. Fonte: Elaboração própria.

De acordo com a classificação climática de Koppen, o clima da região é do tipo semiárido quente (BSh), com temperatura média mensal do mês mais frio superior a 18 ${ }^{\circ} \mathrm{C}$, estação chuvosa no período de fevereiro a abril, precipitação pluvial média anual inferior a $600 \mathrm{~mm}$, e evapotranspiração média anual de $1.600 \mathrm{~mm}$. Os solos da microbacia foram identificados como: Luvissolo Crômico Vértico - TC (Bruno NãoCálcico Vértico), Vertissolo Cromado Órtico - VC (Vertisol) e Neossolo Litólico - RL (Solo Litólico), ocorrendo em 55,6\%, 22,4\% e 7,9\% da área, respectivamente (CHAVES et al., 2002). A vegetação desta é formada por florestas Subcaducifólicas e Caducifólicas, nativas das áreas semiáridas com predominância da caatinga, além da algaroba e as áreas de cultivo (culturas anuais e campos de palma).

\section{Diagnóstico socioambiental}

Foram aplicados questionários previamente estabelecidos, nas propriedades rurais da microbacia hidrográfica e áreas circunvizinhas, tomando-se como aspectos 
sugestivos as questões propostas por Rocha (1997), adaptadas à área de estudo. As principais características organizacionais foram identificadas objetivando um completo diagnóstico das condições gerais: econômicas, sociais, ambientais e tecnológicas. Os questionários foram aplicados por residência e por família, considerando-se diversas variáveis: sociais (demografia, habitação, nível de instrução e participação em organização social); econômicas (produção agrícola, animais de trabalho e de produção, uso econômico da vegetação, comercialização, crédito e rendimentos); e tecnológicas (uso de irrigação, recebimento de assistência técnica e utilização de máquinas agrícolas). A aplicação dos questionários foi feita seguindo a nomenclatura da Secretaria de Saúde do município, através da mobilização de Agentes Comunitários de Saúde, que atuam na micro-área da microbacia hidrográfica do Riacho Namorado e no seu entorno. Ao todo, foram aplicados 25 questionários aos proprietários das unidades rurais, conforme Tabela 1.

Tabela 1: Número de questionários aplicados nas propriedades rurais da microbacia hidrográfica Riacho Namorado, no município de São João do Cariri-PB.

\begin{tabular}{c|c|c|l}
\hline $\begin{array}{c}\text { Micro-área } \\
\text { do Agente } \\
\begin{array}{c}\text { Comunitário } \\
\text { de Saúde }\end{array}\end{array}$ & $\begin{array}{c}\mathbf{N}^{\circ} \text { de } \\
\text { propriedades } \\
\text { rurais }\end{array}$ & $\begin{array}{c}\text { Questionários } \\
\text { Aplicados (\%) }\end{array}$ & \multicolumn{1}{c}{ Comunidades Rurais } \\
\hline 10 & 58 & $19(32,7)$ & $\begin{array}{l}\text { Siriema, Riacho do Piancó, Contendas, } \\
\text { Malhada da Ema, Barbosa, etc. }\end{array}$ \\
\hline 3 & 44 & $6(2,64)$ & $\begin{array}{l}\text { Riacho dos Cachorros, Saco, Fazenda e } \\
\text { Sítio Boa Vista, Olho d'água, etc. }\end{array}$ \\
\hline \multicolumn{2}{r|}{ Fonte: pesquisa de campo (2011) }
\end{tabular}

A partir do registro das coordenadas geográficas (latitude e longitude) de cada propriedade rural onde foi aplicado o questionário, foi possível plotar os pontos obtidos sobre uma imagem de satélite (Fig. 2). Das unidades rurais visitadas, seis estão inseridas na microbacia hidrográfica do Riacho Namorado, caracterizando-se como propriedades relativamente grandes em extensão territorial: Sítio Barbosa (500 ha), Malhadinha da Ema (66 ha), Contendas 1 e 2 (1030 ha), Fazenda da UFPB (384 ha) e Malhada da Ema (250 ha). 


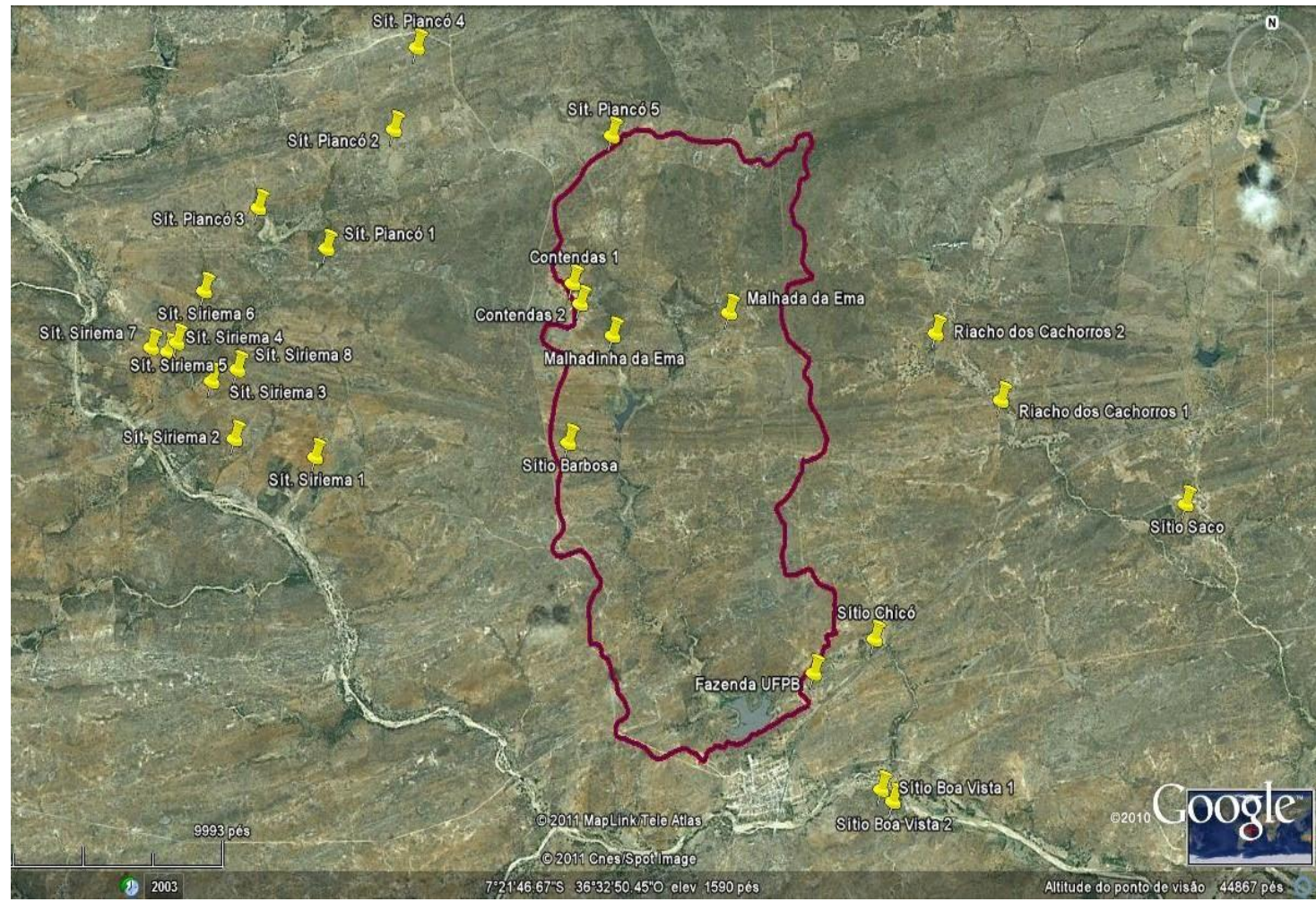

Figura 2: Localização das propriedades rurais (onde foram aplicados os formulários) e delimitação da área da microbacia do Riacho Namorado, no município de São João do Cariri-PB. Fonte: Google Earth (2011)

Os perfis demográfico, social, econômico e ambiental foram estabelecidos, utilizando-se a distribuição de freqüência, sendo os cálculos, análises gráficas e tabelas feitas pela planilha eletrônica Excel. Quanto aos aspectos éticos, todas as etapas deste trabalho obedeceram às diretrizes da Resolução № 196 de 10 de outubro de 1996, onde os participantes foram informados dos objetivos do trabalho, consultados sobre a disponibilidade em participar do estudo e assegurados do sigilo das informações individuais, além de concordarem com a publicação científica dos resultados compilados.

\section{Resultados e Discussão}

\section{Aspectos Sociais}

O diagnóstico social, baseado na demografia, nível de instrução, habitação e participação em organizações sociais constatou que há uma predominância de homens $(58,9 \%)$ em relação às mulheres $(41,1 \%)$, na área da microbacia do Riacho Namorado e 
na sua circunvizinhança, no município de São João do Cariri-PB. Constatou-se que a faixa etária entre 15 e 25 anos é a mais elevada (Fig. 3A). No entanto, destaca-se também uma população compreendida na faixa dos (36 a 46 anos) e (47 a 59 anos), ambas equivalendo a 20,2\%. Este indicador revela que apesar das condições adversas (falta de emprego e de oportunidades para estudar, condições estas alegadas pelos entrevistados durante as visitas), uma população jovem ainda tem permanecido na área rural, demandando empenho e organização de políticas públicas para evitar o êxodo, fazendo com que estes jovens tenham perspectivas de desenvolvimento em seu local de origem.

Com relação ao nível de escolaridade foi observado que 94,9\% dos entrevistados são alfabetizados, sendo que $41 \%$ possuem somente até o quinto ano incompleto, sendo, portanto, um nível de escolaridade baixo para a região (Fig. 3B). O indicativo "outro" refere-se ao nível de terceiro grau e de crianças que ainda não estão estudando. Estudos realizados em localidades próximas a área de São João do Cariri observaram um percentual de $40 \%$ de pessoas não alfabetizadas (Marinho et al., 2009). Diante desse panorama, ressaltam-se a necessidade da criação de cursos de alfabetização e de educação de jovens e adultos que atendam essa população, bem como a criação de cursos técnicos profissionalizantes para os mais jovens, através de projetos sociais de geração de emprego e renda, com o objetivo de estimular a permanência dos mesmos nas propriedades.

Foi constatado um bom percentual de entrevistados considerados da própria região, com $52 \%$ morando na região a mais de 10 anos e $24 \%$ dos moradores nativos, com aproximadamente 20 anos de moradia no local (Fig. 3C). Quanto maior o tempo de residência no local, certamente mais visíveis são as ações de preservação dos recursos naturais e a relação mais harmoniosa com a Terra, devido ao sentimento de pertencimento àquele local.

Foi observado que os integrantes das famílias trabalham na propriedade, constituindo relações de cooperação para compor a renda familiar, embora haja uma reclamação de que faltam empregos formais, o que ocasiona limitações econômicas. As variáveis relacionadas a condição em relação a posse da propriedade evidenciaram que $76 \%$ dos entrevistados são proprietários das terras e $20 \%$ são parceiros, que trabalham em condições assalariadas residindo nas propriedades dos patrões, cuidando dos 
rebanhos dos mesmos, impedidos muitas vezes de terem os seus próprios rebanhos, mas liberados para praticarem agricultura de subsistência. A condição "outra" refere-se à Fazenda da UFCG, conhecida também como Bacia Experimental ou Bacia Escola, que pertence a Universidade Federal de Campina Grande, e que é utilizada como unidade de pesquisas acadêmicas, tendo um fluxo médio semanal de 8 pessoas, contabilizando-se estudantes e funcionários (Fig. 3D). Alves et al. (2011) em Diagnóstico socioambiental realizado para a microbacia do Rio do Saco, Santa Luzia-PB, também encontraram o maior percentual para a condição de proprietário da Terra $(48,27 \%)$, revelando uma boa característica social para a região.

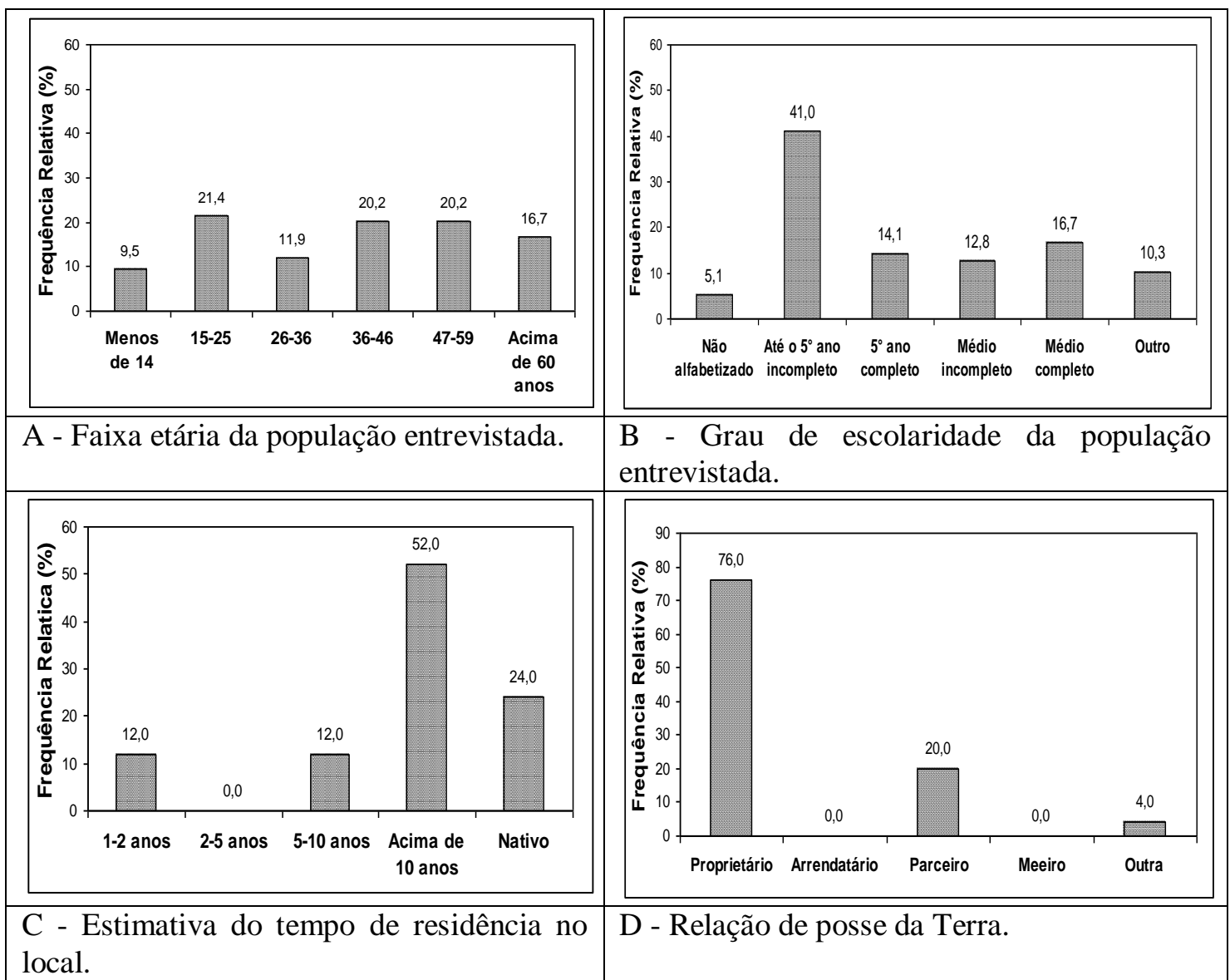

Figura 3: Características sociais da população da Microbacia Hidrográfica Riacho Namorado e circunvizinhança. São João do Cariri - PB. Fonte: pesquisa de campo (2011)

O tamanho das propriedades é demonstrado na Figura 4. Observa-se que, de modo geral, as propriedades são pequenas, não caracterizando uma concentração 
fundiária para a região. Salienta-se que as cinco primeiras propriedades estão contidas na área da microbacia hidrográfica do Riacho Namorado.

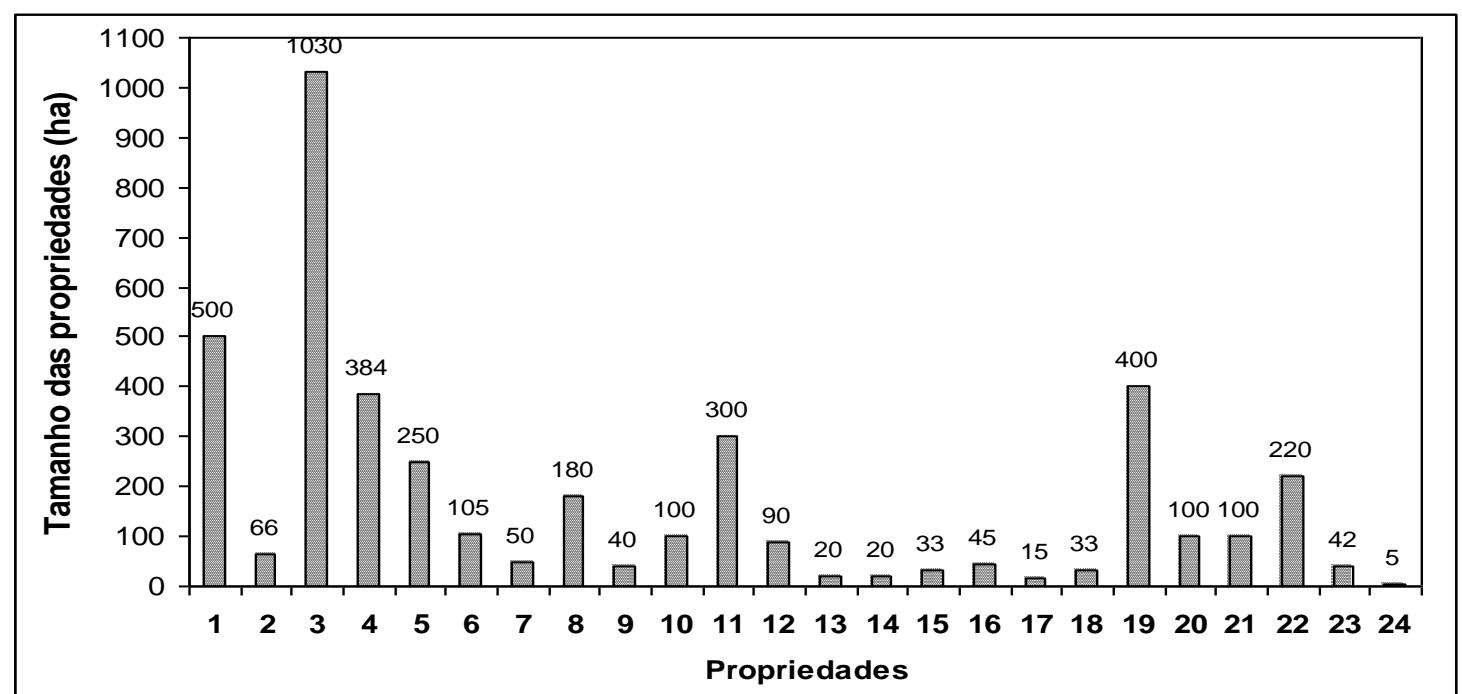

Figura 4: Tamanho das propriedades na microbacia hidrográfica Riacho Namorado e circunvizinhança, no município de São João do Cariri - PB. Fonte: pesquisa de campo (2011)

No que concerne ao tipo de fogão utilizado predominou aquele cuja fonte de energia é o gás GLP associado a lenha, sendo que dentre as duas fontes, foi mencionado o uso mais frequente da lenha. A lenha foi apontada como única fonte de energia por $20 \%$ dos entrevistados (Fig. 5A), ficando evidente a pressão que essa população exerce sobre os recursos vegetais na região, provocando a diminuição das espécies nas proximidades das residências. Não há preferência por espécies vegetais para utilização como fonte energética, sendo utilizadas aquelas que mais facilmente são encontradas. As espécies citadas como mais utilizadas foram: marmeleiro (Croton sonderianus Müll. Arg.), catingueira (Caesalpinia pyramidalis Tul.), aroeira (Myracrodruon urundeuva Allemão) e algaroba (Prosopis juliflora). Convém ressaltar que em estudo realizado anteriormente, Teles (2005) evidenciou que no município de São João do Cariri, $76 \%$ das residências da zona rural utilizam lenha como combustível e $79 \%$ a utilizam por seis a sete dias por semana, de modo que essa realidade energética, no universo rural em estudo, ainda predomina até os dias atuais. Apenas as propriedades localizadas mais próximas a sede urbana municipal usam o gás GLP, certamente devido a logística facilitada de acesso a este recurso energético. A estrutura física das residências, de maneira geral, mostrou-se satisfatória, pois $100 \%$ das residências apresentaram cobertura de telha em um bom estado, revelando um potencial para captação de água de 
chuva, como de fato ocorre. O tipo de habitação identificado foi alvenaria em bom estado para todas as residências, com bom acabamento, diminuindo assim a vulnerabilidade e riscos da população as doenças decorrentes da insalubridade. Outro elemento investigado que apontou indicação de $100 \%$ para a região foi a cobertura de energia elétrica, o que favorece uma melhoria das condições de vida nas propriedades rurais. Não foi identificada nenhuma produção alternativa de energia.

A fonte de água mais utilizada para beber e para o consumo doméstico é a de Cisterna (48\%). As residências que não dispõem desse reservatório informaram o desejo de adquirir essa tecnologia de convivência com a região semiárida. Um percentual significativo (28\%) utiliza a água dos pequenos reservatórios (açudes) dispostos ao longo da rede de drenagem e ainda 20\% utilizam água de poços artesianos (Fig. 5B). Algumas das cisternas foram construídas através do programa 1 Milhão de cisternas (P1MC), coordenado pela Articulação no Semi-Árido Brasileiro (ASA) Brasil, que é uma rede formada por várias organizações da sociedade civil. As demais cisternas foram construídas com recursos próprios dos moradores, através da mobilização social da comunidade. Quando a fonte de água é açude, o transporte é feito através de carroças movidas a força de animais. Esse tipo de abastecimento demanda tempo dos proprietários rurais, sendo uma das primeiras atividades realizadas do dia. Barros (2010) diz que as águas dos pequenos açudes no semiárido estão sendo subutilizadas, uma vez que as perdas por evaporação e vertimento poderiam ser minimizadas pela implantação de usos como a piscicultura extensiva e a agricultura irrigada, com benefícios sociais e econômicos para a região e significativo impacto sobre a fixação do homem no campo e o desenvolvimento da região rural.

Todos os entrevistados informaram que o tratamento da água é realizado com Cloro (Cl), distribuído pelos Agentes Comunitários de Saúde (ACS), e acrescentaram que, em períodos de escassez hídrica, o abastecimento é feito por carros pipas, cuja procedência da água é desconhecida. Esse abastecimento ocasional da operação pipa é feito pelo Exército Brasileiro, que não distribui a água em todas as propriedades, ficando muitas famílias condicionadas a comprar água para o suprimento de suas necessidades. Para uma população não abastada economicamente, esse fato gera vários problemas e dificuldades sociais, ficando clara a problemática da insegurança hídrica na região. 

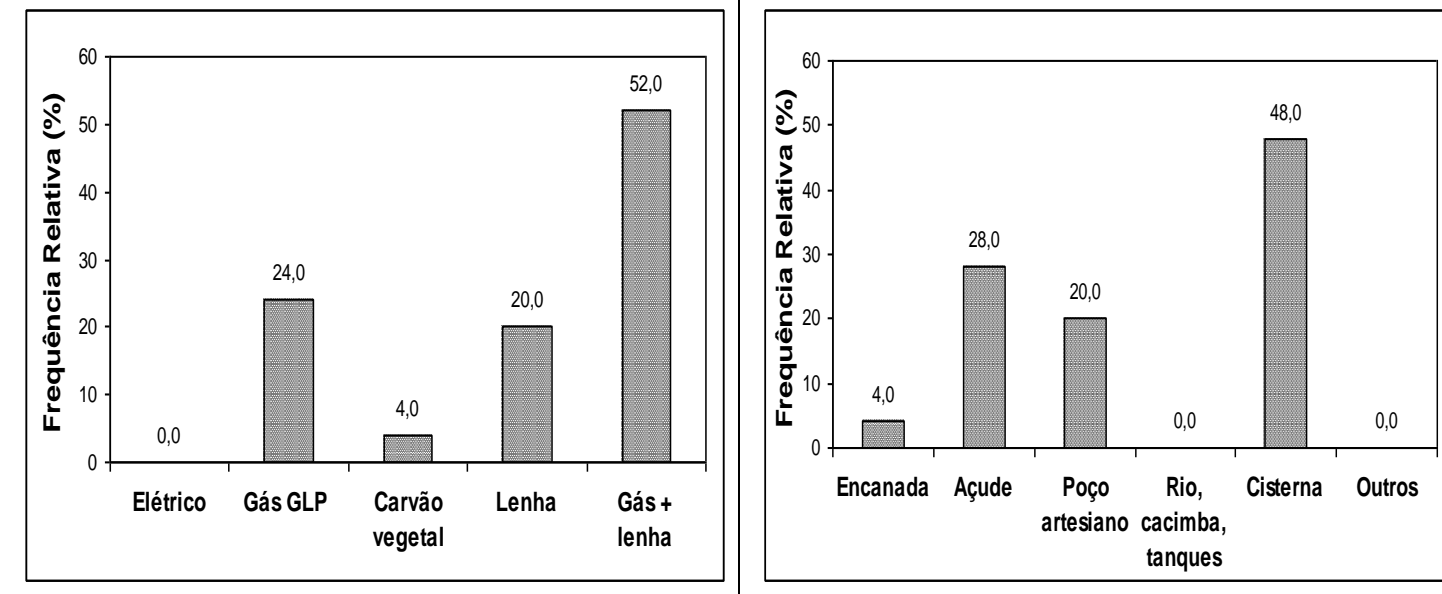

A - Tipo de utilização energética nas B - Tipos de fonte de água. residências.

Figura 5: Fontes de energia e água utilizadas nas propriedades rurais da microbacia hidrográfica Riacho Namorado e circunvizinhança. São João do Cariri - PB.

Fonte: pesquisa de campo (2011).

Foi constatado também que as condições sanitárias são deficitárias nas propriedades rurais. No quesito destino dos dejetos observa-se que em 56\% das propriedades a eliminação é livre (Fig. 6A), ocasionando risco de contaminação das águas superficiais. As fossas sépticas rudimentares foram identificadas em $44 \%$ das propriedades. A Lei 11.445 de 5 de janeiro de 2007, denominada Lei do Saneamento Básico, estabelece diretrizes nacionais para o saneamento básico e institui a Política Federal de Saneamento Básico, que tem como primeiro objetivo a universalização do acesso ao saneamento básico, abrangendo a zona urbana e a zona rural dos municípios. O saneamento básico é um dos principais indicadores da qualidade de vida e do desenvolvimento econômico e social de uma cidade.

Com relação à eliminação dos resíduos sólidos, com exceção da Fazenda da UFCG, que por localizar-se próxima a sede urbana do município de São João do Cariri$\mathrm{PB}$, tem seus resíduos coletados pela prefeitura municipal, dentre outros benefícios como água encanada, as demais propriedades queimam ou eliminam os resíduos livremente no meio ambiente $(60 \%$ e $36 \%)$, respectivamente (Fig. 6B). Os resíduos sólidos apresentam-se como uma questão problemática, pois não há recolhimento por parte da prefeitura. Essa realidade pode ser modificada a partir da implantação de coletores seletivos bem como práticas de educação e conscientização ambiental que visem a minimização da contaminação local, que inclusive pode trazer prejuízos a saúde. Essa situação crítica sanitária também foi identificada por Melo (2010) para as 
sub-microbacias do riacho do Tronco, em Boa Vista-PB, tendo em vista que as propriedades não disponibilizam de rede de esgoto, utilizando fossas sépticas, cujo percentual médio é 53,1\%. Com relação aos resíduos sólidos, em média 78,9\% dos entrevistados enterram ou queimam os mesmos, por não haver sistema de coleta, isso quando não eliminam livremente no ambiente. Dos entrevistados no presente estudo, 64\% não utilizam agrotóxicos em seus cultivos. Os que fazem a administração desses defensivos agrícolas têm o conhecimento de que não devem descartar as embalagens livremente no meio ambiente, portanto queimam (24\%) ou enterram (12\%), como se observa na Fig. 6C. Porém, o correto e recomendado é a devolução das embalagens nos locais de compra, mas já existe uma conscientização mínima de não jogar diretamente no solo ou nos corpos hídricos.

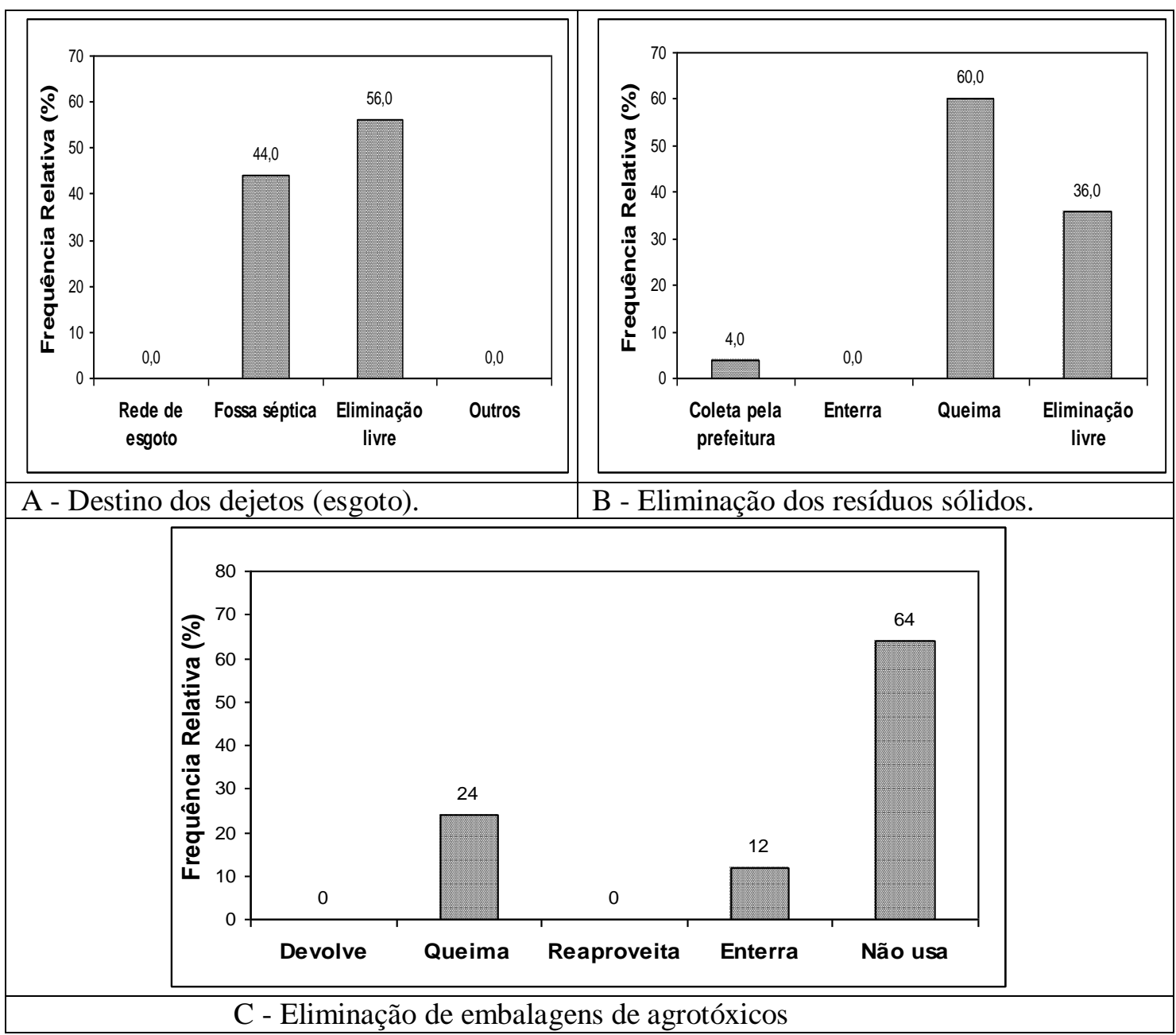

Figura 6: Tratamento dos resíduos sólidos e dejetos na Microbacia Hidrográfica Riacho Namorado e circunvizinhança, no município de São João do Cariri - PB.

Fonte: pesquisa de campo (2011). 
Quanto à variável participação em organização social, apenas $40 \%$ estão integrados em alguma forma de organização social (Tab. 2). As Associações citadas foram: Tanques, Sítio Floresta, Cooperativa de Mulheres de São João do Cariri, Caprinocultores e Sindicato dos trabalhadores rurais de São João do Cariri. Tanques e Floresta são povoados rurais vizinhos as propriedades visitadas. A articulação social é sem dúvidas uma estratégia de organização capaz de prover melhorias das condições de vida para uma determinada região. A associação dos Caprinocultores de São João do Cariri recolhe e armazena o leite que é produzido nas propriedades, que por sua vez é comercializado com representantes do Programa Leite da Paraíba do Governo do Estado. A Associação Tanques, por sua vez, possui mobilização social para construção de cisternas. Apesar dessas ações, essas entidades sociais devem ser mais ativas na busca de melhorias para região, promovendo uma dinâmica econômica maior e possibilitando a formação e capacitação dos proprietários rurais, pois o capital social organizado possui maior representação e força junto aos gestores públicos municipais, estaduais e federais.

Tabela 2: Caracterização da participação da população nas organizações sociais. Microbacia Hidrográfica Riacho Namorado e circunvizinhança, no município de São João do Cariri - PB

\begin{tabular}{c|c}
\hline Participação em organização social & $(\boldsymbol{\%})$ \\
\hline Participam & 40 \\
\hline Não Participam & 60 \\
\hline
\end{tabular}

Fonte: pesquisa de campo (2011).

\section{Aspectos econômicos}

As variáveis observadas para composição do diagnóstico econômico foram: a produção agrícola, produção (quantidade) de animais, animais de trabalho, uso econômico da vegetação, comercialização dos produtos, crédito e rendimentos. As práticas de produção agrícola estabelecidas na região estão relacionadas ao cultivo de mais de três produtos, conforme resposta de $48 \%$ dos proprietários, ficando definida a tradição agrícola na região, ainda que as condições climáticas não sejam tão favoráveis (Tab. 3). Os principais cultivos informados foram milho e feijão. Como cultivos secundários foram identificados a produção de batata, jerimum, sorgo e melancia. A palma e o capim são plantados para serem utilizados como suporte forrageiro, ocupando 
parte das terras nas propriedades. Constatou-se ainda que $56 \%$ dos proprietários realizam produção de horta em cultivo de subsistência, com destaque para o cultivo de frutíferas, como: laranjeira, goiabeira, bananeira, cajueiro e limoeiro e ainda verduras (coentro e cebola), que apesar de serem culturas exigentes são essenciais na dieta alimentar humana.

Tabela 3: Quantidade dos produtos agrícolas. Microbacia Hidrográfica Riacho Namorado e circunvizinhança, no município de São João do Cariri - PB

\begin{tabular}{c|c}
\hline Quantidade de produtos agrícolas cultivados & $(\boldsymbol{\%})$ \\
\hline $0-1$ produto & 8 \\
\hline 2-3 produtos & 44 \\
\hline Mais que três produtos & 48 \\
\hline
\end{tabular}

Fonte: pesquisa de campo (2011).

No que diz respeito à Produção animal (quantidade), o rebanho predominante foi o de ovinos, seguido do rebanho caprino (Tab. 4). Os rebanhos, assim como a agricultura na região, são destinados a subsistência, não havendo praticamente excedente e comercialização da produção. Quando há necessidade de capital, realiza-se a venda de alguns animais para o levantamento de recursos financeiros.

Tabela 4: Quantidade de animais por propriedade rural da microbacia hidrográfica do Riacho Namorado e circunvizinhança. São João do Cariri - PB.

\begin{tabular}{c|c|c}
\hline Rebanhos & $\begin{array}{c}\text { Percentual dos entrevistados em relação } \\
\text { aos rebanhos (\%) }\end{array}$ & $\begin{array}{c}\text { Total de } \\
\text { animais }\end{array}$ \\
\hline Caprinos & 76 & 1316 \\
\hline Ovinos & 64 & 1452 \\
\hline Suínos & 44 & 33 \\
\hline Bovinos & 76 & 497 \\
\hline Aves & 68 & 275 \\
\hline Animais de trabalho & $\begin{array}{c}\text { Percentual dos entrevistados em relação } \\
\text { aos rebanhos (\%) }\end{array}$ & $\begin{array}{c}\text { Total de } \\
\text { animais }\end{array}$ \\
\hline Equinos & 64 & 46 \\
\hline Bois de carroça ou arado & 72 & 23 \\
\hline
\end{tabular}

Fonte: pesquisa de campo (2011).

No tocante a cobertura vegetal, $88 \%$ informaram que as propriedades mantêm mais da metade da vegetação de origem das terras, a caatinga. Porém, acrescentaram a introdução de novas espécies como a algaroba (Prosopis Juliflora DG) e o Nim (Azadirachta indica), este último ainda pouco distribuído na região. A área da 
microbacia do Riacho Namorado, como também as propriedades circunvizinhas estão intensamente colonizadas pela algaroba, principalmente nas margens dos rios.

A Algaroba foi introduzida no semiárido e, naturalmente, através do transporte de sementes pelas águas e pelas fezes de animais, houve um aumento considerável do número dessa espécie nas margens do rio Paraíba, ocupando espaços de reprodução de espécies nativas, como por exemplo, a Craibeira ou Caraúba (Tabebuia caraiba Bur). Segundo Teles (2005), o processo de invasão de um ecossistema por uma espécie exótica se da quando a espécie introduzida se adapta, passando a se dispersar e a alterar o ecossistema. Na caatinga, a introdução da Algaroba ( $P$. juliflora), trazida com o objetivo de constituir uma alternativa econômica para a região, resultou em um processo que já foi classificado como de invasão, segundo vários estudos realizados. Uma espécie exótica é capaz de produzir profundas alterações nos processos ecológicos locais, de modo que é necessário um manejo adequado para evitar a proliferação da mesma.

O uso econômico da vegetação é intenso na região, onde $68 \%$ da população utilizam as espécies vegetais nativas e exóticas para a construção de cercados (Fig. 7A), bem como para utilização como fontes energéticas. Embora para muitas famílias a lenha seja a única fonte energética disponível, essa prática deve ser combatida tendo em vista o desmatamento e a pressão sobre os recursos vegetais causados ao longo dos anos, principalmente das espécies nativas. Melo (2010), que também encontrou valor médio elevado (70,6\%), relacionado a utilização de lenha, para as microbacias do Riacho do Tronco, Boa Vista-PB, acrescenta que é preocupante o fato de que, no semiárido como um todo, a lenha e o carvão não são utilizados apenas para socorrer as necessidades das populações mais pobres, são na verdade usadas em escala comercial para o funcionamento de atividades econômicas, como fornos de padarias, que demandam grande quantidade energética.

Historicamente, a degradação do bioma Caatinga vem se acentuando. A pecuária é intensa desde os primórdios, com a interiorização do gado para o "sertão" provocando desde épocas remotas até os dias atuais um sobrepastoreio, sem um manejo adequado. A infra-estrutura para essa atividade, os currais e cercados, foram feitos utilizando-se estacas e mourões, originárias das espécies vegetais nativas (Fig. 7B).

Os proprietários informaram ainda que vendem a madeira da algaroba, sendo esta alternativa apontada como uma importante maneira de melhorar a renda familiar. 
Essa prática pode ser danosa, na medida em que deixa o solo descoberto, suscetível ao processo de erosão. Além do mais, as espécies menores, consorciadas com a algaroba, podem ser devastas por ocasião da derrubada e retirada da madeira. Atualmente a Superintendência de Administração do Meio Ambiente, órgão ambiental do Estado da Paraíba, com sede em Campina Grande, libera a exploração dessa madeira. Antes essa liberação era realizada pelo Instituto Brasileiro do Meio Ambiente e dos Recursos Naturais Renováveis (IBAMA).

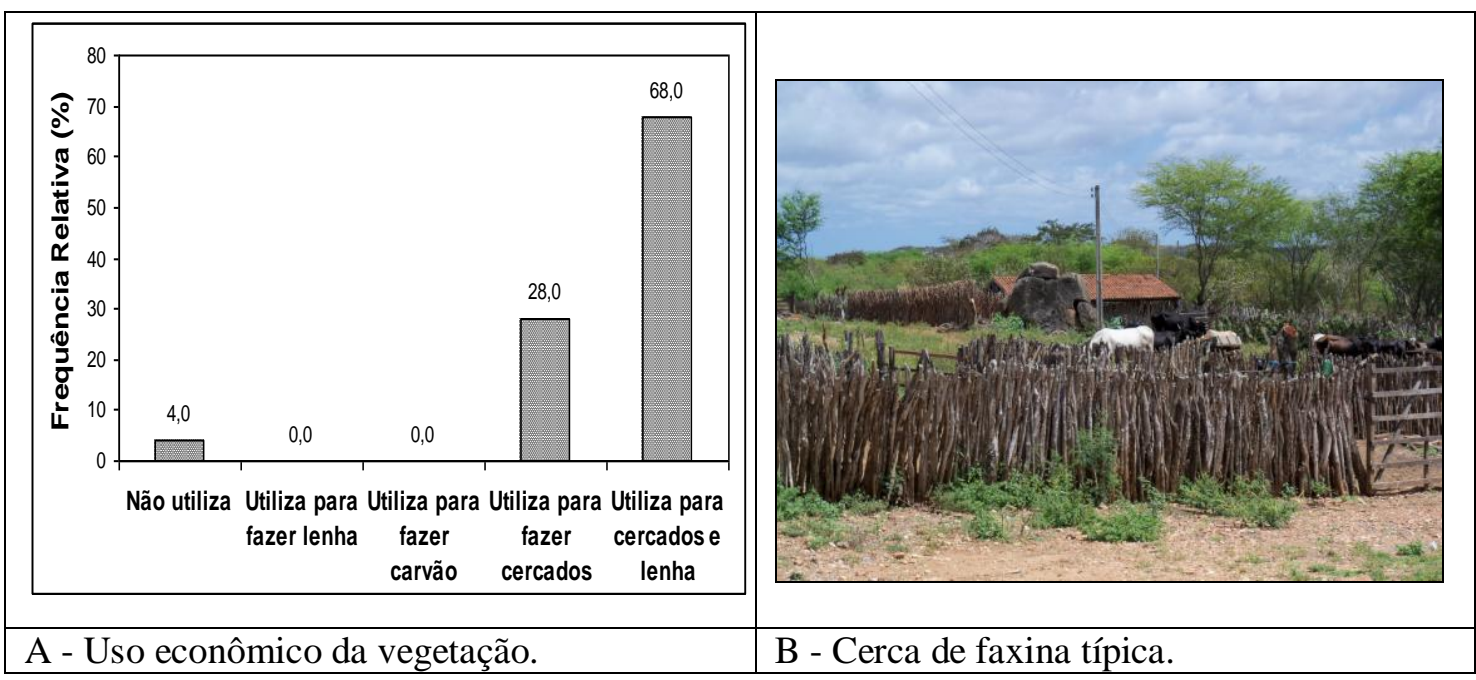

Figura 7: Uso típico da vegetação nas propriedades rurais da Microbacia Hidrográfica Riacho Namorado e circunvizinhança. São João do Cariri - PB.

Fonte: dados e foto dos autores obtidos em pesquisa de campo (2011).

A identificação da atividade principal da propriedade foi realizada a partir da indicação predominante feita por cada entrevistado. Todas desenvolvem simultaneamente atividades de pecuária e agricultura, no entanto uma dessas atividades se sobressai em relação à outra. Para a área de estudo, $72 \%$ dos proprietários afirmaram que a agricultura é ainda a atividade principal, enquanto $24 \%$ indicaram a pecuária (Fig. 8A). Devido às condições climáticas da região, a agricultura é praticada de maneira incerta (cultivo de sequeiro, temporário) subordinada às condições de umidade naturais, que limitam muito a produção local. Na pecuária destacam-se os rebanhos ovinos e caprinos, estes últimos são espécies bastante adaptadas as condições ambientais locais. O indicativo "outra" corresponde a função exercida pela Fazenda da UFPB, que representa um ambiente de pesquisas, constituindo um laboratório natural, mas que dispõe de expressiva criação de caprinos e ovinos. No tocante a questão da renda foi 
observada que há uma predominância do valor mínimo, em que (64\%) das pessoas recebem apenas valores que correspondem até um salário mínimo. Ninguém recebe acima de três salários, ficando um percentual de $36 \%$ com renda entre um e dois salários (Fig. 8B). Para complementação das informações referentes à composição da renda da comunidade, indagou-se sobre o recebimento de bolsas ou auxílios do governo e se existem aposentados no núcleo familiar.

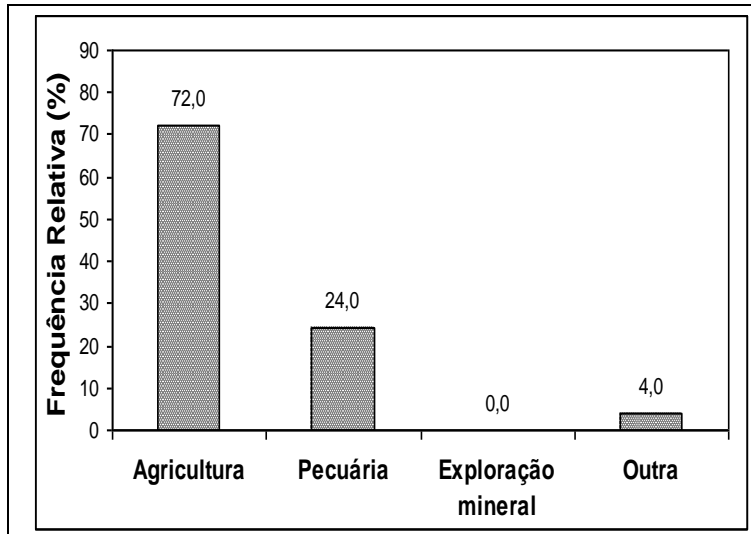

A - Principais atividades desenvolvidas.

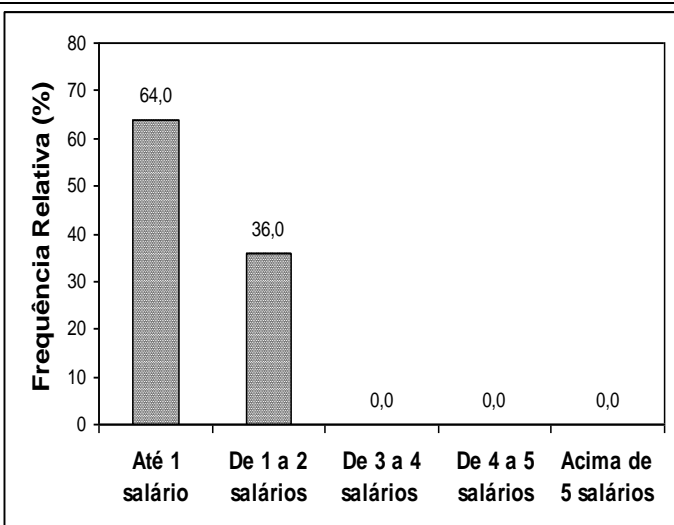

B - Demonstração da Renda familiar.

Figura 8: Exploração e rendimentos das propriedades na Microbacia Hidrográfica Riacho Namorado e circunvizinhança. São João do Cariri - PB.

Fonte: pesquisa de campo (2011).

Deste modo, foi constatado que $48 \%$ recebem esses benefícios, identificados como: Bolsa família e Seguro Safra e 60\% dos entrevistados moram com aposentados (Tab. 5). Sendo assim, essas fontes de renda "fixas" permitem um melhor planejamento orçamentário, não ficando na dependência somente da produção agropecuária da propriedade, que muitas vezes é insuficiente para a manutenção das famílias.

Tabela 5: Composição e origem da renda familiar na Microbacia Hidrográfica Riacho Namorado e circunvizinhança. São João do Cariri - PB

\begin{tabular}{l|c|l|c}
\hline \multicolumn{2}{c|}{ Recebe algum auxílio do Governo? } & \multicolumn{2}{c}{ Mora com aposentados? } \\
\hline Sim & $48 \%$ & Sim & $60 \%$ \\
\hline Não & $52 \%$ & Não & $40 \%$ \\
\hline
\end{tabular}

Fonte: pesquisa de campo (2011).

Quando questionados sobre a venda da produção, 68\% afirmaram que desenvolvem uma pecuária e agricultura de subsistência, e quando precisam vender algum excedente, os varejistas locais são os mais procurados (Fig. 9A). Com relação à 
acessibilidade ao crédito, observa-se na região que $76 \%$ das pessoas não têm fonte de crédito. Foi constatado durante as entrevistas que os proprietários evitam ao máximo recorrer a empréstimos, que são oferecidos a juros elevados. Mas quando precisam de capital extra, $16 \%$ optam pela aquisição junto aos bancos formalizados, enquanto $8 \%$ procuram agiotas (Fig. 9B).

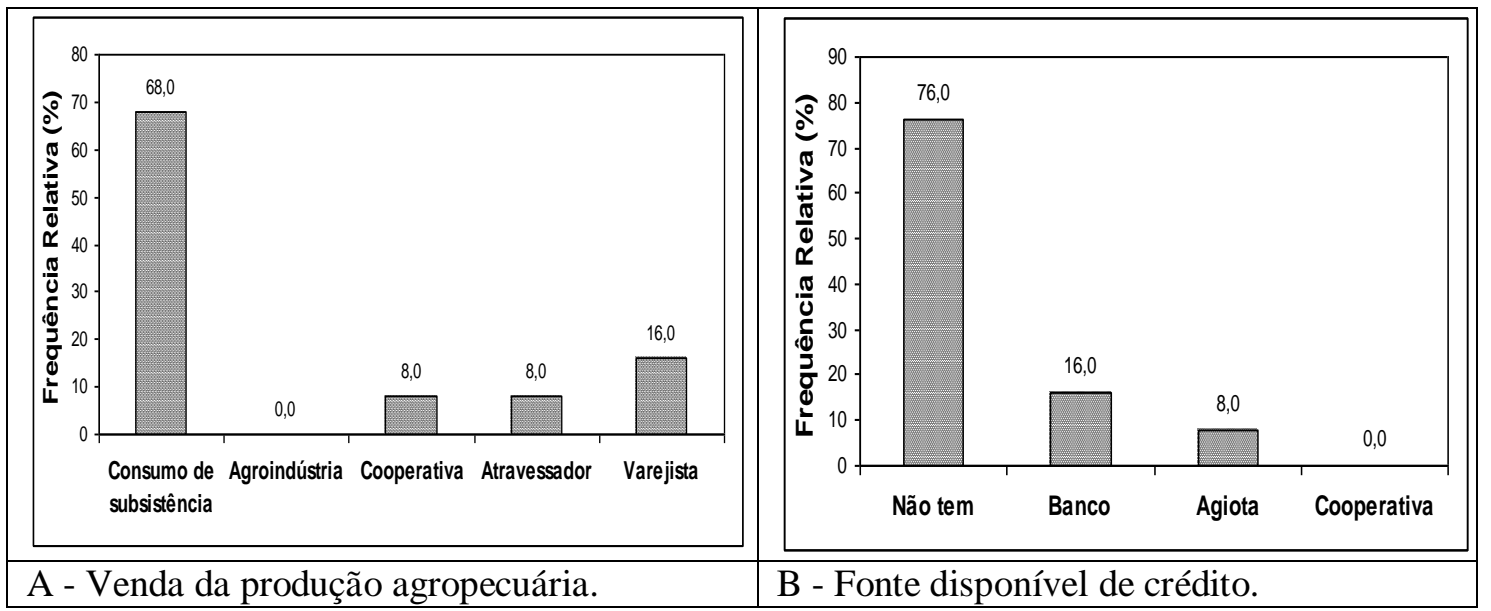

Figura 9: Produção e disponibilidade de crédito na Microbacia Hidrográfica Riacho Namorado e circunvizinhança. São João do Cariri - PB. Fonte: pesquisa de campo (2011).

\section{Aspectos Tecnológicos}

Como aspectos tecnológicos foram analisados as práticas agrícolas e os equipamentos utilizados para melhorar a produção e as condições de vida locais, a exemplo do recebimento de assistência técnica, uso de irrigação, posse de máquinas agrícolas, dentre outras. A Tabela 6 informa sobre a visita de técnicos da Empresa de Assistência Técnica e Extensão Rural da Paraíba (EMATER), ou de alguma outra entidade de fornecimento e divulgação de conhecimentos técnicos e apoio ao produtor, que é fundamental para acompanhar os processos rurais, que conduzam a um desenvolvimento sustentável. A referida tabela indica que (68\%) das propriedades não recebem visitas desses técnicos, ficando assim a população desassistida. Apenas $32 \%$ recebem estas visitas, mas a regularidade é necessária. 
Tabela 6: Recebimento de assistência técnica na Microbacia Hidrográfica Riacho Namorado e circunvizinhança. São João do Cariri - PB.

\begin{tabular}{l|l}
\hline \multicolumn{1}{c|}{ Assistência Técnica e Extensão Rural } & \% \\
\hline Ocasional & 32 \\
\hline Não recebe & 68 \\
\hline
\end{tabular}

Fonte: pesquisa de campo (2011).

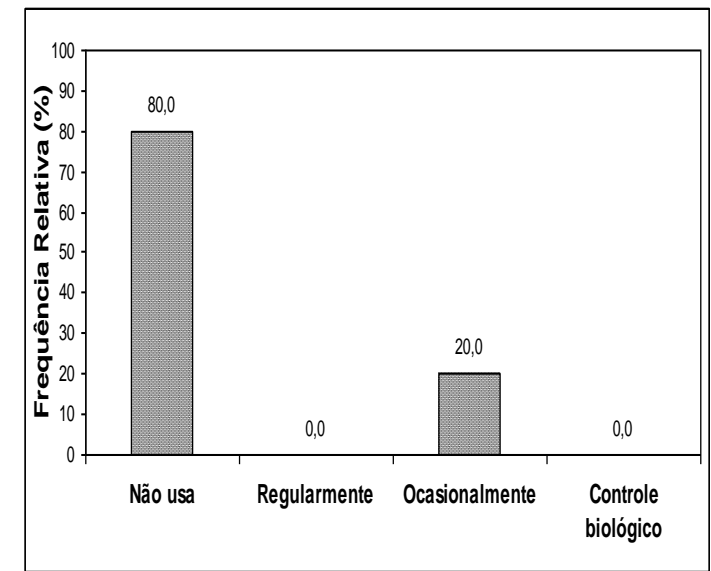

A - Pesticidas e agrotóxicos.

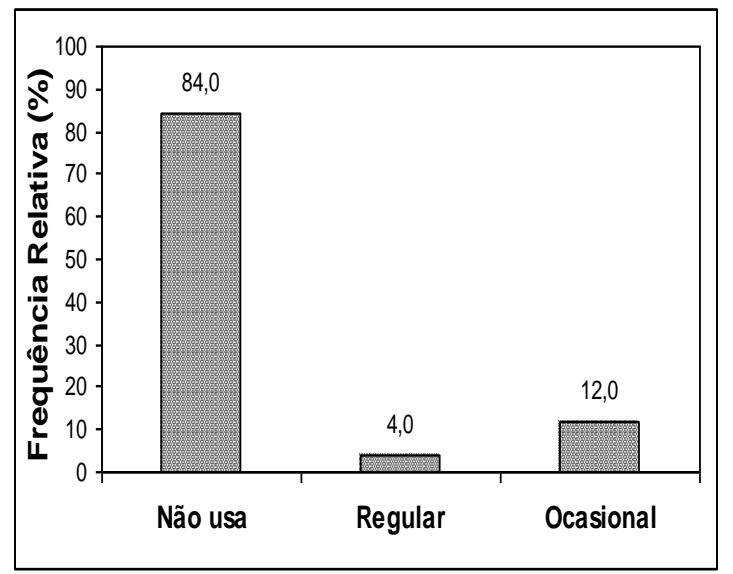

B - Irrigação.

Figura 10: Uso de defensivos agrícolas e irrigação na Microbacia Hidrográfica Riacho Namorado e circunvizinhança. São João do Cariri - PB. Fonte: pesquisa de campo (2011).

No tocante a disponibilidade de equipamentos agrícolas, observou-se que (56\%) dos entrevistados não disponibilizam de nenhuma máquina agrícola, o percentual (44\%) que informou ter algumas, mencionaram principalmente a forrageira, máquina para moer milho e equipamentos para condução hidráulica (Tab. 7). Essa tabela informa ainda sobre o beneficiamento de produtos na propriedade, onde $(80 \%)$ não realiza nenhum tipo de beneficiamento e (20\%) realizam o beneficiamento do leite, produzindo queijo e manteiga para comercialização em feiras locais e em municípios vizinhos.

Tabela 7: Aspectos tecnológicos da microbacia hidrográfica Riacho Namorado e circunvizinhança, no município de São João do Cariri - PB.

\begin{tabular}{l|c|l|c}
\hline \multicolumn{2}{c|}{ Possui máquinas agrícolas? } & \multicolumn{2}{c}{ Realiza o beneficiamento de algum produto? } \\
\hline Nenhuma & $56 \%$ & Sim & $20 \%$ \\
\hline Algumas & $44 \%$ & Não & $80 \%$ \\
\hline \multicolumn{2}{l}{ Fonte: pesquisa de campo (2011). }
\end{tabular}




\section{Conclusão}

O diagnóstico socioambiental do entorno da Microbacia Hidrográfica Riacho Namorado, no município de São João de Cariri-PB permitiu concluir que:

1) A população rural apresenta uma distribuição de faixa etária equilibrada, nível de escolaridade fundamental incompleto, são proprietários das terras e residentes a mais de dez anos na região;

2) As famílias utilizam lenha associada ao gás GLP como fonte energética;

3) As principais fontes de água são cisternas e açudes e os resíduos sólidos são queimados ou eliminados livremente no ambiente;

4) A agropecuária representa a principal atividade econômica das propriedades, com produção basicamente para a subsistência das famílias e a renda familiar é limitada a um salário mínimo.

\section{Referências Bibliográficas}

ALVES, T. L. B.; ARAUJO, A. R.; ALVES, A. N.; FERREIRA, A. C.; NOBREGA, J. E. da. Diagnóstico Ambiental da Microbacia Hidrográfica do Rio do Saco, Santa Luzia - PB. Revista Brasileira de Geografia Física, v. 02, p. 401-417, 2011.

ANA. Agência Nacional de Águas. Conjuntura dos Recursos Hídricos no Brasil: informe 2011. Disponível em: < http://www2.ana.gov.br/Paginas/default.aspx >. Acesso em: 10 dez. 2011.

BARROS, S. V. A. Otimização dos usos múltiplos em pequenos açudes na bacia do Açude de Sumé-PB. 2010, 147p. Dissertação (Mestrado em Engenharia Civil e Ambiental) - Universidade Federal de Campina Grande, Campina Grande, 2011.

BOTELlHO, R. G. M. \& SILVA, A. S. da. Bacia Hidrográfica e Qualidade Ambiental. In: VITTE, A. C.; GUERRA, A. J. T. (Orgs.). Reflexões sobre a Geografia Física no Brasil. Rio e Janeiro: Bertrand Brasil, 2004. p. 153 - 188.

CHAVES, L. H. G.; CHAVES, I. B.; VASCONCELOS, A. C. F.; SILVA, A. P. P. Salinidade das Águas Superficiais e Suas Relações com a Natureza dos Solos na Bacia Escola do Açude Namorado e Diagnóstico do Uso e Degradação das Terras Relatório Técnico, UFPB, Campina Grande, v. 1, 114 p, 2002.

IPA. Instituto Agronômico de Pernambuco. Cochonilha - Praga da palma forrageira. Disponível em:< http://www.ipa.br/resp8.php>. Acesso em: 20 set. 2011. 
LAMONICA, M. N. Impactos e reestruturação da gestão dos recursos hídricos na bacia hidrográfica do Rio São João - RJ. 2002. 112 f. Dissertação (Mestrado em Geografia) - Universidade Federal Fluminense, Niterói, 2002.

MARINHO, C. F. C. E.; MONTEIRO, A. S.; ALMEIDA, H. A.; Perfil

socioeconômico e ambiental das comunidades que circundam a microbacia hidrográfica do açude Epitácio Pessoa. In: XIX Encontro Nacional de Geografia Agrária. São Paulo: 2009 Anais... XIX ENGA. 1 CD-ROM.

MARTINHO, V. J. P. Reflexões Sobre o Desenvolvimento Rural. Millenium, n. 19, p. 09, 2000.

MELO, J. A. B. Diagnóstico físico-conservacionista e das vulnerabilidades como subsídio ao ordenamento territorial da microbacia do riacho do Tronco, Boa Vista, PB. 218 f. Tese (Doutorado em Recursos Naturais) Universidade Federal de Campina Grande, Campina Grande, 2010.

ROCHA, J. S. M. Manual integrado de bacias hidrográficas. Santa Maria: Edições da UFSM, 1997, $446 \mathrm{p}$.

TELES, M. M. F. Cobertura vegetal do município de São João do Cariri - PB: I Distribuição espacial da Caatinga II - Uso de lenha como fonte de energia. 2005. 61 f. Dissertação (Mestrado em Agronomia) - Universidade Federal da Paraíba, Areia, 2005.

VILAÇA, M. F.; GOMES, I.; MACHADO, M. L.; VIEIRA, E. M.; SIMÃO, M. R. L. Bacia Hidrográfica como unidade de Planejamento e Gestão: O estudo de caso do Ribeirão Conquista no município de Itaguara - MG. In: Simpósio Brasileiro de Geografia Física Aplicada, 8, 2009. Anais... UFV, 2009. 1 CD-ROOM.

Recebido para publicação em abril de 2012 Aprovado para publicação em julho de 2012 